\title{
New Sociotechnical Insights in Interaction Design
}

\author{
José Abdelnour-Nocera ${ }^{1}$ and Anders I. Mørch ${ }^{2}$ \\ ${ }^{1}$ Centre for Internationalisation and Usability, Thames Valley University \\ St Mary's Road, London, UK, W5 5RF \\ Jose.abdelnour-nocera@tvu.ac.uk \\ ${ }^{2}$ InterMedia, University of Oslo \\ P.O. Box 1161 Blindern, N-0318 Oslo, Norway \\ anders.morch@intermedia.uio.no
}

\begin{abstract}
New challenges are facing interaction design. On one hand because of advances in technology - pervasive, ubiquitous, multimodal and adaptive computing - are changing the nature of interaction. On the other, web 2.0, massive multiplayer games and collaboration software extends the boundaries of $\mathrm{HCI}$ to deal with interaction in settings of remote communication and collaboration. The aim of this workshop is to provide a forum for HCI practitioners and researchers interested in knowledge from the social sciences to discuss how sociotechnical insights can be used to inform interaction design, and more generally how social science methods and theories can help to enrich the conceptual framework of systems development and participatory design. Position papers submissions are invited to address key aspects of current research and practical case studies.
\end{abstract}

\section{Introduction}

One of the biggest challenges for $\mathrm{HCI}$ and $\mathrm{CSCW}$ is addressing the ongoing tensions created by the gap between social requirements and the affordances of technical design [1]. The translation of social knowledge into design decisions is not a simple problem, but one that requires a redefinition of disciplinary boundaries and the subject and object of interaction design. Addressing this socio-technical gap requires a fresh look at how diverse areas of the social sciences explore and conceptualize the relation between people, society and technology under the rubric of 'sociotechnical'. While organizational studies of technology adoption have a well-defined conceptual framework known as sociotechnical systems theory with established principles [e.g. 2] the situation is not the same for interaction design research. While perspectives like ethnography, ethnomethodology [3] and activity theory [4] have problematized and stimulated the design of interactive systems, the potential contribution of other social science perspectives such as American Pragmatism [e.g. 5,6] or the Sociology of Technology [e.g. 7] are beginning to appear, providing new experiences to extend the existing work.

This workshop aims to gather researchers in HCI and CSCW who work on expanding the connection between social science research and interaction design practice 
under the umbrella 'sociotechnical'. The challenge is to achieve some level of 'translation' between the two domains of discourse in order to improve the design of interactive systems. This workshop is the second in a series of workshops that started in London in 2008 as an event jointly organized by the Interactions and Sociotechnical specialist groups of the British Computer Society. The workshop led into a special issue in the International Journal of Sociotechnology and Knowledge development in 2009 [8].

\section{Goals and Topics}

The goal is to enable new translations from the social sciences to interaction design. The topics include, but are not limited to, the following areas: overview of related work in HCI and CSCW; critiques of earlier approaches to design; related work on sociotechnical design (e.g. participatory design, organizational informatics); actionable recommendations and guidelines for the conception, design and evaluation of interactive systems as 'social proxies'; improved methods for the gathering and elicitation of 'social requirements'; identifying socially responsible policies for interaction design; interaction design for web technology and social networking (e.g. web 2.0); using theories from the social sciences to inform interaction design; understanding participatory design as a sociotechnical endeavor in software engineering (e.g. agile methods; end-user development). It is hoped this workshop will foster dialogue between academics in different disciplines (e.g. HCI, CSCW, Sociology, Psychology, Anthropology, Marketing, Software Engineering, Ergonomics, Education, Information Systems) interested in interdisciplinary research in interaction design.

\section{References}

1. Ackerman, M.: The intellectual challenge of CSCW: the gap between social requirements and technical feasibility. Hum.-Comput. Interact. 15, 179-203 (2000)

2. Mumford, E.: The ETHICS approach. Commun. ACM 36, 82 (1993)

3. Dourish, P., Button, G.: On "Technomethodology": Foundational Relationships Between Ethnomethodology and System Design. Human-Computer Interaction 13, 395-432 (1998)

4. Kaptelinin, V., Nardi, B.A.: Acting with Technology: Activity Theory and Interaction Design. MIT Press, Cambridge (2006)

5. Barnes, S.: The Contemporary Relevance of George Herbert Mead's Social Psychology and Pedagogy. Philosophical Studies in Education 33, 55-63 (2002)

6. Mørch, A.I.: From Pragmatism to Interaction Design: A Sociotechnical Design Space. International Journal of Sociotechnology and Knowledge Development, Special issue on Sociotechnical Systems and Interaction Design 1(2), 8-22 (2009)

7. Abdelnour-Nocera, J., Dunckley, L., Sharp, H.: An Approach to the Evaluation of Usefulness as a Social Construct using Technological Frames. International Journal of Human Computer Interaction, Special Issue about Field Research Methods 22(1), 157-177 (2007)

8. Abdelnour-Nocera, J., Eason, K., Beale, R.: New Sociotechnical Insights in Interaction Design. International Journal of Sociotechnology and Knowledge Development 1, i-iii (2009) 